\title{
HUBUNGAN MOTIVASI KERJA DENGAN KINERJA KARYAWAN AKPER PANTI KOSALA SURAKARTA
}

\author{
Oleh: \\ Endang Dwi Ningsih ${ }^{1}$,Tri Susi Wulandari ${ }^{2}$,Aan Daryanto ${ }^{3}$
}

\begin{abstract}
Introduction: Motivation is the human psychological characteristics that contribute to a personal commitment's level, these are included the causal factors, to aplicate and keep maintaining the human behavior into a certain purposed direction. Performance is someone working achievement. The motivation gives a significant contribution to increase the working performance of employees.

The objective of the study: To know the relation between motivation with working performance of the Nursing Academy Panti Kosala Surakarta employees.

The Subject of the study: The 33 person of the Nursing Academy Panti Kosala employees. Sampling technical used is saturated sampling, there for all of the subject are used as the sample.

The datas are collected by questionnaire method for both variable, the motivation and the employees working performance, analyzed by Chi Square test.

The result: By Chi Square test used SPSS for windows series 18 with $\alpha=5 \%$ ( $0.05)$, the value of $p=0.000,(p<0.05)$, is the hypothesis received.

The study conclusion: There is any relation between motivation with working performance Nursing Academy Panti Kosala Surakarta employees.
\end{abstract}

Keywords: Working motivation, employee performance

\section{PENDAHULUAN}

Bekerja adalah suatu bentuk aktivitas yang bertujuan untuk mendapatkan kepuasan. Aktivitas ini melibatkan fisik dan mental. Bekerja itu merupakan suatu aktivitas fisik dan mental manusia dalam mencapai tujuannya. Sedangkan pengertian motivasi adalah suatu kondisi yang berpengaruh untuk membangkitkan, mengarahkan, dan memelihara perilaku yang berhubungan dengan lingkungan kerja. (Nursalam, 2011)

Motif adalah kondisi seseorang yang mendorong untuk mencari suatu kepuasan atau mencapai suatu tujuan. Jadi motif adalah suatu alasan atau dorongan yang menyebabkan seseorang berbuat sesuatu, melakukan tindakan, atau bersikap tertentu. Bisa juga dikatakan bahwa motivasi berarti membangkitkan motif, membangkitkan daya gerak, atau menggerakkan seseorang atau diri sendiri untuk berbuat sesuatu dalam rangka mencapai suatu kepuasan atau tujuan. (Sobur, 2011)

Motivasi adalah karakteristik psikologis manusia yang memberi kontribusi pada tingkat komitmen 
seseorang. Hal ini termasuk faktorfaktor yang menyebabkan, menyalurkan, dan mempertahankan tingkah laku manusia dalam arah tekad tertentu. Tiga poin penting dalam pengertian motivasi yaitu hubungan antara kebutuhan, dorongan, dan tujuan. Kebutuhan muncul karena adanya sesuatu yang dirasakan kurang oleh seseorang, baik bersifat fisiologis ataupun psikologis. Dorongan merupakan arahan untuk memenuhi kebutuhan tersebut, sedangkan tujuan adalah akhir dari suatu siklus motivasi. (Suarli dan Yanyan, 2010)

Kinerja adalah hasil kerja yang dapat dicapai oleh seseorang atau sekelompok orang dalam suatu organisasi, sesuai dengan wewenang dan tanggung jawab masing-masing, dalam rangka upaya mencapai tujuan organisasi bersangkutan secara legal, tidak melanggar hukum dan sesuai dengan moral dan etika. (Sinambela, 2012) Penilaian kinerja merupakan alat yang paling dapat dipercaya dalam mengontrol sumber daya manusia dan produktivitas. Proses penilaian kinerja dapat digunakan secara efektif dalam mengarahkan perilaku pegawai dalam rangka menghasilkan jasa terkait dengan kualitas dan volume yang tinggi. (Nursalam, 2011)

Manajemen kinerja yang efektif adalah langkah bagi tercapainya tujuan organisasi, yang memberikan dampak pada landasan bisnis. Dengan menguasai keterampilan penting ini, karyawan akan dapat menyusun pengaturan yang lebih baik bagi kepentingan organisasi dan kepentingan karyawan. (Ellis, 2005)

Motivasi kerja memberikan sumbangan yang signifikan dalam meningkatkan kinerja karyawan karena setiap karyawan akan termotivasi apabila kebutuhan yang menjadi sarana untuk hidup dapat terpenuhi dengan baik, kebutuhan ini mulai dari kebutuhan fisiologis sampai kebutuhan aktualisasi diri. Karyawan yang kebutuhan hidupnya terpenuhi, akan memberikan kinerja yang semakin besar dalam melaksanakan tugas dan kewajibannya.

Berdasarkan pengamatan awal dari peneliti ditemukan masalah yang berkaitan dengan kinerja karyawan Akademi Keperawatan Panti Kosala Surakarta, sebagian karyawan bekerja dengan baik dan sungguhsungguh dan sebagian lagi menunjukkan sikap seenaknya sendiri bahkan terkesan bekerja hanya untuk menunggu jam kerja selesai, maka peneliti tertarik untuk mengetahui apakah tipe kinerja karyawan tersebut terkait dengan motivasi bekerja.

Berdasarkan uraian latar belakang di atas, maka peneliti tertarik melakukan penelitian tentang "Hubungan Motivasi Kerja dengan Kinerja Karyawan Akper Panti Kosala Surakarta".

\section{TUJUAN PENELITIAN}

Secara umum penelitian ini bertujuan untuk mengetahui hubungan antara motivasi kerja dengan kinerja karyawan Akper Panti Kosala. Adapun tujuan khusus penelitian ini adalah (1) Untuk mengetahui tingkat motivasi kerja karyawan Akademi Keperawatan Panti Kosala Surakarta. (2) Untuk mengetahui tingkat kinerja karyawan Akademi Keperawatan Panti Kosala Surakarta.

\section{DESAIN PENELITIAN}

Penelitian ini merupakan penelitian analitik dengan desain korelasi dan pendekatan cross sectional. Korelasi merupakan jenis rancangan yang 
mengkaji hubungan antar variabel yaitu mengungkapkan hubungan korelatif antara variabel motivasi kerja sebagai variabel bebas dengan kinerja karyawan sebagai variabel terikat. Sedangkan desain cross sectional merupakan rancangan penelitian yang pengukuran atau pengamatannya dilakukan secara simultan pada suatu saat (sekali waktu). (Hidayat, 2008)

\section{POPULASI, SAMPEL, DAN TEKNIK SAMPLING}

Populasi adalah merupakan seluruh subyek atau objek dengan karakteristik tertentu yang akan diteliti. Bukan hanya objek atau subjek yang dipelajari saja tetapi seluruh karakteristik atau sifat yang dimiliki subjek atau objek tersebut. (Hidayat, 2008) Populasi pada penelitian ini adalah karyawankaryawati Akper Panti Kosala Surakarta sejumlah 33 orang.

Sampel merupakan bagian populasi yang akan diteliti atau sebagian jumlah dari karakteristik yang dimiliki oleh populasi. (Hidayat, 2008) Pada penelitian ini peneliti mengambil sampel 33 orang karyawan karyawati Akper Panti Kosala Surakarta.

Dalam penelitian ini, peneliti menggunakan seluruh karyawan Akper Panti Kosala sebagai sampel, maka teknik sampling yang digunakan adalah teknik sampling jenuh yaitu cara pengambilan sampel dengan mengambil semua anggota populasi menjadi sampel. (Hidayat, 2008)

\section{HASIL PENELITIAN}

Penelitian dilakukan mulai bulan November 2014 - Februari 2015 dengan responden karyawan karyawati Akper Panti Kosala Surakarta sebanyak 33 orang. Di bawah ini akan dipaparkan hasil penelitian tentang hubungan motivasi kerja dengan kinerja karyawan Akper Panti Kosala Surakarta.

Tabel 1. Distribusi frekuensi variabel motivasi kerja pada karyawan Akper Panti Kosala

\begin{tabular}{cccc}
\hline No & $\begin{array}{c}\text { Motivasi } \\
\text { Kerja }\end{array}$ & $\mathrm{F}$ & $\%$ \\
\hline 1 & Tinggi & 27 & $81,8 \%$ \\
\hline 2 & Sedang & 5 & $15,2 \%$ \\
\hline 3 & Rendah & 1 & $3 \%$ \\
\hline & Jumlah & 33 & $100 \%$ \\
\hline
\end{tabular}

Dari tabel di atas ditemukan frekuensi paling banyak pada motivasi kerja kategori tinggi yaitu 27 responden $(81,8 \%)$, sedangkan frekuensi paling sedikit pada motivasi kategori rendah yaitu 1 responden (3\%).

Tabel 2. Distribusi frekuensi variabel kinerja karyawan Akper Panti Kosala Surakarta

\begin{tabular}{cccc}
\hline No & $\begin{array}{c}\text { Kinerja } \\
\text { Karyawan }\end{array}$ & $\mathrm{F}$ & $\%$ \\
\hline 1 & Tinggi & 30 & $90,90 \%$ \\
\hline 2 & Sedang & 2 & $6,10 \%$ \\
\hline 3 & Rendah & 1 & $3 \%$ \\
\hline & Jumlah & 33 & $100 \%$ \\
\hline
\end{tabular}

Dari tabel di atas ditemukan frekuensi paling banyak pada kinerja karyawan kategori tinggi yaitu 30 responden (90,90\%), sedangkan frekuensi paling sedikit pada kinerja karyawan kategori rendah yaitu 1 responden (3\%).

Berdasarkan hasil uji dengan menggunakan Chi Square dengan program SPSS for Windows seri 18 dengan $\alpha=5 \%(0.05)$ diperoleh $p$ sebesar 0,000 sehingga $p<0.05$, berarti hipotesa diterima maka dapat ditarik kesimpulan bahwa ada hubungan antara motivasi kerja dengan kinerja karyawan Akper Panti kosala. 


\section{PEMBAHASAN}

1. Variabel Motivasi Kerja

Berdasarkan tabel 1 dapat dilihat bahwa frekuensi paling banyak pada motivasi kerja kategori tinggi yaitu 27 responden dan motivasi rendah yaitu 1 responden, hal ini menunjukkan bahwa motivasi kerja karyawan Akper Panti Kosala Surakarta merupakan bentuk karakteristik psikologi manusia yang telah mencapai tingkat komitmen tinggi sehingga akan mampu menyalurkan dan mempertahankan tingkah lakunya dalam arah tekad tertentu sebagaimana yang dikemukakan oleh Suarli dan Yanyan (2010). Hal di atas juga sesuai yang dikemukakan oleh Sobur (2011), bahwa motivasi adalah suatu keadaan dari dalam yang memberi kekuatan, yang menggiatkan atau yang menggerakkan, yang mengarahkan atau menyalurkan perilaku ke arah tujuan-tujuan. Dengan demikian motivasi tinggi yang dimiliki karyawan Akper Panti Kosala Surakarta merupakan kekuatan dari dalam diri karyawan yang akan menggerakkan atau menggiatkan perilaku karyawan ke arah tujuan yang telah ditetapkan oleh organisasi dalam hal ini Akper Panti Kosala Surakarta.

Beberapa teori motivasi yang dikutip oleh Nursalam (2011), adalah:

a. Menurut Maslow, individu akan termotivasi untuk memenuhi kebutuhan yang paling menonjol atau paling kuat pada kurun waktu tertentu.

b. Menurut Mc Clelland mengatakan bahwa pimpinan dapat mencapai tingkat tertentu atau menaikkan kebutuhan untuk berprestasi dengan menciptakan lingkungan kerja yang memadai.

c. Menurut Herzberg pada teori dua faktor, bahwa faktor kepuasan merupakan faktor yang memotivasi antara lain: prestasi, pengakuan, tanggung jawab, isi pekerjaan yang berkaitan dengan imbalan prestasi kerja.

d. Menurut teori keadilan bahwa individu akan termotivasi jika hal yang mereka dapatkan seimbang dengan usaha yang mereka kerjakan.

Berdasarkan kutipan Nursalam (2011) di atas, hal ini sesuai dengan yang terjadi pada karyawan Akper Panti Kosala Surakarta yaitu bahwa karyawan termotivasi untuk memenuhi kebutuhan yang paling kuat yaitu kebutuhan terwujudnya aktualisasi diri sebagai individu, sebagai kepala/anggota keluarga, sebagai anggota masyarakat yang bertanggung jawab karena usia karyawan paling banyak berada pada usia yang produktif antara 30 - 49 tahun $(69,70 \%)$ dan tingkat pendidikan karyawan paling banyak pada tingkat perguruan tinggi yaitu 21 responden (63,60\%) sehingga karyawan secara individu sudah terbentuk menjadi pribadi yang mandiri dalam meningkatkan diri dan kariernya, sebagaimana yang dikutip oleh Nursalam (2011), tentang Teori Harapan bahwa individu mengharapkan konsekuensi tertentu dari tingkah lakunya yang akan berpengaruh pada keputusan tentang bagaimana cara mereka bertingkah laku, hasil dari tingkah laku tertentu mempunyai valensi atau kekuatan untuk memotivasi dan tingkah laku seseorang sampai tingkat tertentu akan bergantung pada tipe hasil yang diharapkan. 
Faktor yang berpengaruh pula adalah kondisi lingkungan kerja senantiasa diciptakan Akper Panti Kosala agar karyawan mampu berprestasi dengan baik dan sehat antara lain dengan penyediaan sarana dan prasarana kerja yang memadai dan kondusif (fisik) dan tersedianya peraturan, norma dan panduan ketertiban (non fisik) yang mengatur kinerja, prestasi, penghargaan (imbalan) dan sanksi demi berlakunya perlakuan yang sama bagi setiap karyawan dan keseimbangan antara yang didapat dengan usaha yang dikerjakan karyawan.

2. Variabel Kinerja Karyawan Berdasarkan tabel 2 menunjukkan bahwa frekuensi kinerja karyawan berada pada kategori tinggi yaitu 30 responden $(90,90 \%)$ dan pada kategori rendah 1 responden (3\%). Dari paparan tabel tersebut, hal ini sesuai yang diungkapkan Nursalam (2011), bahwa faktorfaktor yang mempengaruhi kinerja karyawan mencakup penampilan dan kepuasan kerja antara lain: motivasi, lingkungan (komunikasi, potensial pertumbuhan, kebijakan, gaji dan kondisi kerja yang kondusif), peran pimpinan dan penilaian kinerja.

Faktor-faktor yang tercakup pada kinerja karyawan tersebut telah teraplikasi di Akper Panti Kosala bahkan terus ditingkatkan sehingga pada tingkatan kinerja tinggi diharapkan mampu meningkatkan prestasi organisasi dalam mencapai tujuan secara legal, tidak melanggar hukum dan sesuai dengan moral dan etika. (Sinambela, 2012)
3. Hubungan Motivasi Kerja dan Kinerja Karyawan

Dari hasil uji Chi Square dengan menggunakan program SPSS versi 18 dengan a 5\% $(0,05)$ diperoleh $p$ sebesar 0,000 sehingga $p<0,05$ berarti hipotesa diterima dengan kesimpulan ada hubungan antara motivasi kerja dengan kinerja karyawan Akper Panti Kosala Surakarta.

Menurut Nursalam (2011) salah satu faktor yang mempengaruhi kinerja karyawan adalah motivasi yang meliputi: keinginan untuk peningkatan, memiliki kemampuan pengetahuan, keterampilan dan nilai yang diperlukan, promosi, kerjasama dan peningkatan penghasilan. Maka dengan motivasi tinggi pada karyawan Akper Panti Kosala berbanding lurus dengan kinerja pada kategori tinggi akan memberikan kontribusi yang terus meningkat pada Akper Panti Kosala Surakarta, demikian pula Akper Panti Kosala mampu mengakomodasi kebutuhan karyawan sehingga tercapai kepuasan kerja yang diharapkan karyawan.

Menurut Sinambela (2012), implikasi kinerja berhubungan dengan:

a. Pelatihan: dapat membantu karyawan untuk mengembangkan berbagai keterampilan tertentu yang memungkinkan untuk karyawan berhasil pada pekerjaannya.

b. Kedisiplinan adalah kemampuan kerja seseorang untuk secara teratur, tekun secara terus menerus dengan bekerja sesuai dengan aturan yang berlaku.

c. Kepuasan kerja: berhubungan dengan kinerja karyawan, 
seseorang yang puas dalam pekerjaannya akan memiliki motivasi, komitmen pada organisasi dan partisipasi kerja yang tinggi yang pada akhirnya akan terus mempengaruhi kinerja. Demikian sebaliknya kinerja yang tinggi akan mempengaruhi kepuasan kerja yang akhirnya memunculkan keterikatan pada organisasi.

Berdasarkan paparan di atas maka motivasi yang tinggi akan menghasilkan kinerja yang tinggi sehingga peningkatan kompetensi karyawan Akper Panti Kosala pada pelatihan bermanfaat pada pengembangan dan penyelesaian pekerjaannya, kedisiplinan dapat menjadikan karyawan terus meningkatkan kepatuhan pada aturan yang berlaku dan kepuasan kerja karyawan memunculkan keterikatan karyawan Akper Panti Kosala Surakarta pada organisasi. Diharapkan dengan pelatihan, kedisiplinan dan kepuasan kerja karyawan Akper Panti Kosala mampu meningkat secara kualitas dan kuantitas kerja.

\section{KESIMPULAN}

Terdapat 27 responden yang memiliki motivasi tinggi dengan kinerja tinggi, 5 responden yang memiliki motivasi tinggi dengan 3 responden memiliki kinerja tinggi dan 2 orang responden dengan kinerja sedang dan terdapat 1 responden yang memiliki motivasi rendah dengan kinerja rendah.

Dari hasil uji Chi Square dengan menggunakan program dan SPSS versi 18 dengan a $5 \% \quad(0,05)$ diperoleh $p$ sebesar 0,000 sehingga $p<0,05$ berarti hipotesa diterima dengan kesimpulan ada hubungan antara motivasi kerja dengan kinerja karyawan Akper Panti Kosala Surakarta.

\section{SARAN}

Sesuai hasil dan kesimpulan, maka hasil penelitian ini dapat menjadi masukan bagi karyawan yang memiliki motivasi tinggi dan kinerja tinggi untuk tetap mempertahankan atau bahkan meningkatkan diri dan perlunya memberi arahan dan pembinaan untuk karyawan yang memiliki motivasi kerja rendah, yang berdampak pada kinerjanya yang rendah pula, agar mencapai kinerja yang baik.

\section{DAFTAR PUSTAKA}

Ellis, Carol W. Management Skills for New Managers. Jakarta: Bhuana IImu Populer, 2005.

Hidayat, Aziz Alimul. Riset Keperawatan dan Teknik Penulisan IImiah. Jakarta: Salemba Medika, 2008.

Metode Penelitian Keperawatan dan Teknik Analisis Data. Jakarta: Salemba Medika, 2009.

Marquis, Bessie L. dan Carol J Huston. Kepemimpinan dan Manajemen Keperawatan: Teori dan Aplikasi. Jakarta: EGC, 2010.

Nursalam. Manajemen Keperawatan: Aplikasi dalam Praktik Keperawatan Profesional. Jakarta: Salemba Medika, 2011.

Sinambela, Lijan Poltak. Kinerja Pegawai Teori Pengukuran dan Implikasi. Yogyakarta: Graha IImu, 2012. 
Sobur, Alex. Psikologi Umum dalam Lintasan Sejarah. Bandung: Pustaka Setia, 2011.

Suarli dan Yanyan Bahtiar. Manajemen Keperawatan dengan Pendekatan Praktis. Jakarta: Erlangga, 2010.

Suyanto. Metodologi dan Aplikasi Penelitian Keperawatan. Yogyakarta: Muha Medika, 2011.

Riwidikdo, Handoko. Statistik Kesehatan dengan Aplikasi SPSS dalam Prosedur Penelitian. Yogyakarta: Rohima Press, 2013.

Harshanty, Andina Widya. Pengaruh Motivasi Terhadap Kinerja Karyawan Badan Perijinan Terpadu (BPT) Kabupaten Sragen. 2014.

Nazaruddin. Hubungan Motivasi Kerja dengan Kinerja Pegawai di Badan Kepegawaian Daerah dan Diklat (BKDD) Kabupaten Maros. 2012.

1. Dosen AKPER Panti Kosala

Surakarta

2. Mahasiswa AKPER Panti Kosala Surakarta

3. Mahasiswa AKPER Panti Kosala Surakarta 